Case report

\title{
A First Encounter of Residents of a Long-Term Care Facility with Virtual Reality Glasses
}

\author{
Victoria Mühlegger * \\ Akademie für Altersforschung am Haus der Barmherzigkeit ; victoria.muehlegger@altersforschung.ac.at \\ * Correspondence: Victoria.muehlegger@altersforschung.ac.at; Tel.: 004369914013897
}

\begin{abstract}
In this study, 6 residents of a long-term care facility were asked to try on Virtual Reality glasses and report their first experiences with Virtual Reality. The results show that Virtual Reality is of great interest to elderly residents of in-patient long-term care facilities. The wearing period was longer than expected and no symptoms of cyber sickness occurred. For the residents it was exciting to explore the virtual environments. Austrian destinations, nature scenes in the mountains and forests but also trips to the zoo, the museum, in churches or even densely populated areas like shopping streets or train stations would be places for the residents, they would like to explore virtually. Far-off destinations such as Rio de Janeiro or the Caribbean are more of an exception. Biographically relevant places such as the parental home or the location of their wedding were not named. Concerning the usability, an adjustment of the VR glasses is necessary for a longer-term use in any case.
\end{abstract}

Keywords: long-term care, technology, therapy, virtual reality

\section{Introduction}

The demographic change, in addition to low birth rates and the increasing employment of women, cause an aging society. More and more people are reaching a higher age. People today age differently than they did a few decades ago, today's "elderly" stay fit and active for a longer time, but they are not necessarily healthier than 60 years ago [1]. People born in the 1940s still benefit from the economic boom of the 1950s and 1960s, as the food, housing and work situation has steadily improved. Knowledge and technology in the medical field has improved immensely and awareness for prevention rose. While increasing prosperity has helped to prolong life, now the symptoms of obesity and physical inactivity are significant challenges today. Medicine provides us with the subjective feeling of a longer, fitter life than it did 60 years ago, but we have not become much healthier overall [1].

Even though the period, in which people depend on care and support due to health restrictions might continue to shift further forward, the future of elderly care is dominated by the shortage of trained professionals, which seems. to be more relevant than ever before. To provide the elderly with the proper care they need is a key challenge for the health system [2]. Multigenerational households that used to care for the elderly and dependent family members are becoming increasingly rare in the west-ern world, so in-patient long-term care is becoming more and more important alongside ambulant care services.

The settlement to a long-term care facility is influenced by various aspects. It is not only a question of health and the support of the social environment, but another focus of this adaption process involves the influence on the quality of life and independence of the elderly person [3]. Elderly people are more likely to move to a care facility if they are over 84 years old and widowed, live alone and have at least developed mild form of dementia [4]. Due to its particular challenges, dementia is the number one cause for institutionalization among the elderly, followed by cardiovascular diseases [5]. Between $25-50 \%$ of the admissions to a nursing home are directly or 
indirectly caused by incontinence [6]. Relocation to a nursing home can no longer be averted if severe physical suffering, cognitive impairment, poor social structures, unfavorable housing conditions that are not suitable for the elderly and unacceptable family relationships have become a burden for the person or the family [7].

The entry into a care facility is to be regarded as a critical life event, since it concerns a potentially drastic and stressful situation in the life of a person and has a large influence on the further life and must first adapt to the new situation [7]. The subjective assessment of the situation is therefore of particular importance for the future of the new resident. Moving into a long-term care facility can be seen as a relief, since professional nursing support is available at any time [3]. On the other hand, moving to a long-term care facility can also be perceived as a burden, as the own home has to be left behind and the upcoming life change is counteracted with uncertainty and worry. Often there is a "forced voluntary" of moving to a care facility, as people see no other option but professional support [3].

Self-determination is threatened if independence decreases due to the need for care [8]. It refers to the characteristics of nursing homes in the sense of the so called total institution, in which the bureaucratic organizational structure and the concomitant standardization puts the individuality of the clients into the background [9].

Extensive information of the everyday life of average residents of a long-term care institution is rare, since the residents interviewed for their everyday life usually do not have cognitive impairments such as dementia and therefore they only represent a small proportion of nursing home residents [8]. Residents of long-term care facilities are very diverse, not only because of their degree of dependency and ill-nesses, but also because of their mobility, cognitive status, age and biography.

The circumstances and conditions of a long-term care facility structure the residents' everyday life strictly [8]. In addition to the fixed times for breakfast, lunch, snacks and dinner, the times for daily care and activities are often predetermined. Residents of long-term care facilities spend their spare time between these appointments with conversations, cognitive training or reading. Much of the interaction is directly focused on the nursing staff. Residents without cognitive impairments mainly criticize leisure program that are perceived as kindergarten-like, obtuse activities, obviously, the interests of the various groups of residents are often given too little consideration [8].

\subsection{Virtual Reality}

Virtual Reality (VR) is a computer technology that uses special VR glasses, so called head-mounted dis-plays, to create an immersive sensation of physical presence in interactive three-dimensional environments [10], realistic or artificially created environments, and 360-degree images as well as videos to visit places visually without having to leave the room.

The special feature of the novel three-dimensional technology is the increased degree of immersion, which could not be achieved with previously existing display technologies such as LCD or LED. Because of this immersive presentation, the presence experience, defined as the subjective feeling in the computer-generated reality, is truly to be there [11].

Although many studies state using Virtual Reality based application for many different causes with the elderly, such as training of motor and cognitive deficits [12], it seems as Virtual Reality has been interpreted extensively, using Nintendo Wii [13] or big screens [11] as a technology for Virtual Reality. Elderly people in particular can benefit from VR technology [14], but due to their incomplete technology biography, they are a difficult target group for technological innovations [15]. Especially as the products are designed by members of young and middle-aged adults, 
difficulties might occur. Adjustments in fit, shape, size and weight of VR glasses should be considered when using Virtual Reality with the elderly [16]. In addition, adjustments to the limitations of vision and hearing are also essential [17].

However, participation in social life can be severely restricted by mental performance and physical health. People, who live in in-patient long-term care facilities often only have restricted opportunities to autonomously leave the facility and attend places of choice. It is not only the physical limitations that prevent this form of autonomy, also institutional framework, chronic shortage of staff and lack of relatives make it difficult for residents to go places.

Residents could use VR glasses to tour memories by visiting their home, their favorite beach, or other locations. Virtual Reality creates new kinds of conversations and memories with powerful, interactive content, such as games. Attractions such as Macchu Picchu can be toured as a group or a walk through beautiful cities adds variety to everyday life. Through the combination of Virtual Reality and therapy, like physical therapy or occupational therapy, new experiences can be collected and new stories can be told [18].

However, despite the potential of VR technology, the use for the elderly is not easy to implement. The innovation is so abstract compared to other technical approaches that it might be a big challenge to introduce older people to this technology. Due to the novelty of the technology there are still big deficiencies in the handling of the VR glasses. Therefore, the operation of the device should be taken over by a companion, in order not to overtax the elderly users. The goal of using Virtual Reality among older people in need of care must never be a reduction of personal care [15].

Also, cyber sickness is a risk of Virtual Reality. If the virtual three-dimensional environment is in motion, symptoms such as headache, dizziness, and nausea may occur, as the visual system senses movement, but the proper movement of the body is absent [19]. Therefore, it is recommended to select appropriate content for the target group and rather to forego dynamic videos and interactivity [15].

\subsection{Problem statement}

By moving to a long-term care facility, elderly people are confronted with the need to change their habits after a long, independent life in their own home and to adapt to the environment of the facility. Many residents of long-term care facilities have fewer social contacts and no opportunities for self-determinated activities due to their physical limitations in order to gain positive reinforcement. In addition to the hospital-like ambience of care facilities, the lack of opportunities for retreatment has an effect on the well-being of people in need of care [20].

With Virtual Reality goggles adapted to the needs of the users, it is possible to visit places that would be difficult or impossible for people with disabilities to go to in reality. Visiting favorite places, using Virtual Reality glasses can not only relieve stress and strengthen resilience of the elderly patients but also sup-port nursing staff and relatives in various ways [21].

In a previous project, aspects relevant to the design and use of virtual reality applications for the elderly have been formulated. The way of approaching the new technology and the acceptance based on it seems to be especially important. Due to the complete lack of awareness of VR technology, the target group needs a slow, extensive pre-accession phase [14]. Biography-related content could be a motivational support to deal with the new technology. However, the formulated aspects of using VR technology represent theoretical assumptions that are not empirically substantiated. 


\subsection{Purpose of the study}

Goal of this project was a first meeting of residents of a long-term care hospital with a VR-glasses. In the process, the first impressions of the inhabitants were recorded and suitable contents for the introduction to Virtual Reality glasses were identified.

\subsection{Research Questions}

The study was conducted to answer following questions.

Question 1: How do the first encounters of elderly people with Virtual Reality work?

Question 2: Which motives and sensations accompany the first encounter of the elderly with Virtual Reality?

2a: Which fields of application of VR glasses exist from the perspective of the residents?

2b: Which virtual scenarios do the participants wish to visit?

\section{Materials and Methods}

\subsection{Research Design}

For the implementation of this empirical work a qualitative approach was the method of choice, since other approaches did not fit this setup, because other technologies were used instead of headmounted displayed Virtual Reality. Because no literature or empirical findings on the subject could be retrieved, therefore, an inductive, hypothesis-generating method was used.

Problem-centered interviews with six residents of a care hospital in Vienna, Austria were conducted. As a supplement, participant observations were used with two residents to document their first meeting with Virtual Reality. As part of the procedure, after informing them about the project, the residents were asked to consent to join the project. First the participants were explained how the glasses work and afterwards they tried the glasses on themselves. For the first experience of Virtual Reality a simple nature scene was used. Based on the first VR experience, the interview was conducted using a semi-structured guide. In addition, a short questionnaire on relevant sociodemographic data was collected.

\subsubsection{Sampling}

The following requirements to the selection of interviewees were applied:

- Resident of the Care Hospital in Vienna, Austria

- No dementia diagnosis (Mini Mental State Examination > 24)

- No or little vision restrictions

- Equal gender distribution of interviewees

- Voluntary participation in the interview

As an incentive to participate in the interview, the residents were given either a small bouquet of flowers or a lottery ticket.

The insights gained in this study should serve as a foundation for the optimization process of using Virtual Reality for the elderly and for the definition of potential use cases of Virtual Reality in a long-term care facility from the perspective of the residents.

\subsection{Data collection}

For gathering the data for the analysis, a problem-centered interview was conducted. The problem-centered interview according to Witzel is a method combination of qualitative interview and case analysis [22], in which already existing concepts may be modified by the utterances of the 
interlocutors [23]. It is a combination of induction (empirical) and deduction (theoretical), and thus comes closer to reality, since researchers do not enter into a conversation completely without theory and concept [23]. Based on the transcribed interviews, a case analysis was conducted. Using codes, the content of the interview was assigned sentence by sentence. Subsequently, case reports were formulated, from which an overall context was developed and cross-case central topics were worked out [22].

In two randomly selected participants, in addition to the interview, a participant observation was also carried out while trying the VR glasses. Participatory observation is considered a basic social science method used as a complement to other methods [23]. It is essential for the conduct of a participatory observation that it is unstructured, for example that no observation scheme is developed in advance in order to be open and without expectations of observation [23].

The observation was carried out covertly, because the participants who were trying out the glasses were not explicitly pointed to the observation so as not to influence it. During the test phase observations were recorded using notes. The observation served both as a theory development and as an ex-amination, but not only the recording of the observations is used for the interpretation, but additional information, such as the interview, is also taken into account [23].

The notes logged during the testing were viewed, structured and formulated during the evaluation phase.

\subsubsection{Testing}

The interviews were conducted in the residents' rooms and lasted approximately 45 minutes, including the information on Virtual Reality and trying out of the VR glasses. Three of the residents also kept the glasses on during the interview. With the consent of the participants, the interview was recorded on tape.

\subsubsection{Analysis}

For the analysis of the interviews, the recommendation for the evaluation of problem-centered inter-views was followed. The interview files were transcribed using the F4 transcription software. In order to achieve a good readability, the texts were smoothed and dialect corrected.

The transcripts were assigned to the upper and lower categories using F4 analysis software. If stat-ments could be assigned to several categories, they were also coded according to several categories. Subsequently, case reports were formulated and cross-case topics were identified.

\subsection{The Virtual Reality glasses}

For this study, a Samsung Gear VR 2017 and a Samsung Galaxy S8 was used, as it is a lowthreshold, easy-to-use VR glasses. Compared to higher-end VR glasses, you do not need a high-end, high-performance computer that processes the virtual software. In the Samsung Gear glasses, a smartphone is used, which takes over both the computing power and the image reproduction. One focus of the selection of the terminals used was also the reasonableness of the financial outlay. Since the smartphones of recent years (Samsung and Apple) are currently the most widely used devices, only about 80 euros would be spent on the glasses, which is rather a small financial burden compared to other technological devices.

The comfortable design of the glasses allows a high wearing comfort, no matter which head shape or face structure, with the head straps adjustments of the size can be made. The glasses have a wide field of view of $101^{\circ}$ which ensures a clear and fascinating VR experience. Smooth and precise head tracking through the built-in position sensor and accelerometer means the 360-degree environment can be viewed without faltering or shaking [24].

For the implementation of the study, a specially hygiene-friendly foam pad was provided, which can be disinfected, as it is shown in Figure 3. After each use, the glasses were completely wiped with disinfect-ant. For the presentation of the 360 degree environments, the app 360 Photos was used. As an initial environment, an image of Pfänder Mountain was used, which is shown as a screenshot in 
Figure 4, but the representation on the glasses is 360 degrees three-dimensional. The landscape is located in Vorarlberg on Lake Constance with a view to Constanz, Germany.

\section{Results}

\subsection{Description of the sample}

The participants of this study are six residents of the Haus der Barmherzigkeit Pflegekrankenhaus Seeböckgasse in Vienna, Austria. In order to recruit the residents, the ward managers were informed about the project and asked to name residents to whom these inclusion criteria apply to. The residents were informed about the project and asked if they would be interested in participating. The six residents agreed to participate in the project and an appointment was made to try out the VR glasses and the interview. The appointment with a gentleman was postponed once, because he was busy playing a card game. The fact that neither a dementia diagnosis nor a stronger vision impairment exists was checked with the consent of the residents in the electronic care documentation system.

The sample consisted of three women and three men aged between 68 and 80, who live in one of the geriatric wards in the care hospital. The period of residence varied between 5 and 13 years. Five of the residents had to rely on a wheelchair, a lady used a walker for mobility.

The majority of the participants had already participated in a project for audiovisual stimulation as a non-medical sleep supplement. The Happy Med glasses are television glasses, which showed four different nature scenes with music.

Although the Virtual Reality glasses are completely different from the technology of the Happy Med glasses, they are comparable in terms of the setting. For anonymization, the participants were named in random order with the letters A-F.

\subsection{Analysis}

To get a better impression about the VR exposure, detailed information about the qualitative analysis and two case reports are given as an example in 3.3 and 3.4.

\subsubsection{Qualitative coding}

Personal

This category includes all the content of the conversation that allows conclusions to be drawn about the personality of the interviewees.

Everyday life

The category and its subcategories include all information that describes the all-day-design of the interviewees.

The category "Everyday life - earlier" includes all information on how the interview partners used to design their everyday life. The information is then subdivided into the subcategories health status, activities, family and career.

The category "Everyday Life - today" includes all information on how the interview partners are structuring their everyday lives in the care facility today. The information is then subdivided into the subcategories Health Condition, Activities (Excursions and Therapy) and Family.

\section{Technology}

The category includes all the information that was given on the topic of technology, the subcategories cover the attitude to technology and the use in general, and in particular the attitude towards Virtual Reality and risks and disadvantages associated with the technology.

VR experience

The category includes all information about trying out the VR glasses and related topics that came up in the interview. The subcategories include possible uses (further differentiated into change / seeing new things / distraction, relaxation and therapy), feelings, motives and emotions that are 
connected with the VR glasses as well as the presence experience and aspects that could make the exposure even more exciting.

Places and destinations

The category includes personal destinations that the interviewees have travelled, the environments the people on the VR glasses visited, and destinations they would like to see with the VR glasses.

3.3 Ms. A.

\subsubsection{Sociodemographic data}

Age: 80 years

Gender: Female

Former occupation: saleswoman

Duration of stay: 6 years

Mobility: wheelchair

Health restrictions: osteoporosis, scoliosis, spinal anterior artery syndrome

MMSE: 30

Ms. A. is very positive and intends to privacy and voluntarism. Further liabilities are rejected. She is rather withdrawn and takes her health fate well, is very aware of her abilities and limitations and has learned to deal with it. Ms. A. is very positive towards technology that she can benefit from and rejects social media and television networks with commercial breaks. Her husband died shortly before retirement, she has daughters.

\subsubsection{Participating observation}

Mrs. A. is in her room; the appointment was made in the week before. At the beginning she is given information about the VR glasses. The glasses are being set and she puts them on. Ms. A. looks around, she turns her head and automatically reaches for the tires of her wheelchair and turns around a little. With the right hand, she is holding the glasses, the weight seems. to be too high or the glasses are not adjusted adequately. While touching the glasses on the right side, she also touches the touchpad to adjust the image. "Oh, that's nice to look at!" says Ms. A. "Now I see the mountains, the snow (..) and there are two people there". Ms. A. is likely to have adjusted the glasses by accident. "They are skiers, yes." Ms. A. has her index finger and middle finger on the touchpad. Excitedly, Ms. A. reports what she sees.

The question of whether she still sees the same picture as in the beginning seems. to be overheard, she is very immersed in her virtual environment and tells what she sees. She always moves her wheelchair back and forth or turns sideways. She points in front of her. "And now the snow is gone, the bare wall, the gray floor, the earth and there is now a bench and a wall", Ms. A. describes the pictures she sees, that the picture seems to be changing does not disturb her. Ms. A. keeps holding the VR glasses with both hands now and continues to tell eagerly what she sees. When asked if she is now looking at different pictures, she happily answered "Yes, that's very nice to look at, yes", "There it is green (.) And now everything is gone. (...)". Ms. A. bends forward and backwards, she looks around.

Ms. A. keeps holding her glasses when asked if the glasses are too heavy for her, she does not answer, she may not have heard, she is too busy exploring the virtual environment. "And there are trees and there is a roof where you can be, and there are books down there. And the carpet is not well rolled ", Ms. A. laughs. She may have touched the touchpad several times and returned to the home screen, a virtually created Oriental library. Again, I ask Ms. A. if the glasses are very heavy, "NO, NOT AT ALL!", answers Ms. A. quickly, "I like it!", She has already submerged again and continues 
to report in many words about what she sees. She gestures wildly with her hand, pointing around the room, "The books down there (..)".

Ms. A. turns around with the wheelchair and sees areas of the 360-degree picture she has not seen yet "I have not seen that yet, because I would have had to turn my wheelchair!" She explains to me. Mrs. A. seems. to have a good understanding of the glasses. "But now I've turned and now I've seen it!", She continues to describe what she encounters in the virtual environment. She keeps turning and dares to make bigger moves, while the observer makes sure she does not bump into the furniture.

"Very nice to watch," says Ms. A. with the afterthought "for those who want to use it". For herself, she says she is interested in the technology.

\subsubsection{Interview}

Everyday life - earlier

Ms. A. worked as a salesperson. She was married and has daughters. Her husband died shortly before retirement. She never had time for vacation and was busy with other things, or if there had been time, she did not want to go on journeys.

Everyday life - today

Ms. A. structures her everyday life very self-confident. Using the wheelchair gives her mobility, so she can make her rounds through the care facility, picking up the newspaper, going outside or on the terrace. In activities, she is rather passive and likes to observes the happenings. She takes good care of her room and spends a lot of time reading. Excursions, for example to the Technical Museum, would interest her, but there are currently no excursions on her ward.

\section{Technology}

She is open to technology if it gives her more benefits than disadvantages. She rejects TV channels with commercial breaks and social networks because of she views it as an invasion of her privacy. She uses a cell phone and the TV with teletext to catch up on news. Ms. A. is enthusiastic about the VR glasses, "it can show wonders!". When asked if the glasses are associated with risks or disadvantages, she answers "No, ABSOLUTELY NOT!".

\section{VR experience}

Feelings, motives and emotions

When asked how she liked the VR glasses she answers: "Very well. Actually quite normal." she repeats the feeling" normal " several more times and later explains the following dimensions: "Yes, I had the feeling, as if I saw what was around me just if I was there. There I am now (..) I know anyway that I am in my wheelchair, but I see something in front of me, something beautiful.". What places she wants to explore with the glasses, Ms. A. explains enthusiastically: "EVERYTHING! No matter! All around, every-thing in the world!". "Everything, it does not matter. You cannot be so choosy; you can just look at everything.".

Ms. A. recognizes on her own that the variety of scenarios that can be displayed on the glasses is virtually unlimited. She does not want to be picky and would like to explore any virtual environment. In connection with the glasses, Ms. A. emphasizes the voluntary aspect to use the glasses: "That's up to you! Who wants (..) should try it, who does not want to does not have to. You cannot force a person to do something". The safety aspect of virtual trips is also relevant to her experience "I am not exposed to danger, somewhere on the mountain. Nothing could fall on my head like a rock or a snow avalanche or something".

\section{Presence Experience}

Ms. A. would like to have a more intense feeling of presence, especially in natural scenes with animals she can imagine auditory enhancements: "Yes, that can be done. For example, you can hear birds singing on a mountain pasture or something, in the countryside. Or you show a forest where 
6 of 13

the animals are. And you may hear the animals, or you can hear the cuckoo calling. (laughing) Or what do I know, what animals are might be there?".

Use cases

Ms. A. would like to use the VR glasses in everyday life, "and a bit to explore other environments.". Not only for herself she could imagine the use of the glasses, but: "In the day room, where the residents are sitting the whole day, with the glasses they would still be in the day room and yet in a different environment, in which they can go around like this or something. ". Also: "Yes, maybe in therapy with the therapists! There you could use it to. Everything is possible!". Since there are currently no excursions on the ward Ms. A. would like to go on a virtual museum tour with the VR glasses.

Places and destinations- Already visited

Ms. A. had been visiting only destinations in Austria.

Places and destinations - Seen with the VR glasses

While trying out the glasses, Ms. A. unintentionally touched the control panel and switched to other pictures of the photo series and the launch environment. Ms. A. is unaware that she has carried out the change of images and has therefore not noticed anything negative. "What have I seen? Landscape, skiers, mountains, snow-capped mountains, (.) And then an alpine pasture or something. There are a gentleman and a lady, family sat at a table. Then, a restaurant? Somehow, like a pub, with a bar and tables and a couch, and a bed and books and stairs to go up somewhere.".

Places to visit with the VR glasses

The destination that Ms. A. wants to visit with her glasses can be summed up as follows: "Everything that moves in the world". "It could be people! It does not just have to be animals. People, roads, shop-ping centers, railway stations.". Also she referred to examples such as museums, churches, destinations within Austria, but also the Caribbean or underwater, Ms. A. remains rather unspecific. "It does not matter. (laughs)". She is just interested in the whole world. "EVERYTHING! The whole world, what it is. Africa too. Or what do I know what there is. The jungle.".

\subsection{Mr. B.}

\subsubsection{Sociodemographic data}

Age: 76 years

Gender: Male

Former occupation: electrician / bodybuilder

Duration of stay: 13 years

Mobility: wheelchair

Health limitations: Insult with hemiplegia and aphasia

MMSE: $24+3$ without assessment because of physical impairments

Mr. B. is very interested in technology and also uses computers, e-mails, etc. Since a stroke, Mr. B. has been living in the care hospital for a very long time and is training with his therapists for his linguistic and motor impairments to improve. Due to the linguistic impairment, Mr. B. speaks rather short sentences and single words. Therefore, in the interview, the statements given by Mr. B. were paraphrased in order to ask whether the meaning was understood correctly. In conversation, Mr. B. laughs a lot, partly to dub his linguistic impairment partly also because of joy.

\subsubsection{Participating observation}

Mr. B. is sitting in his room in a wheel chair at the time of the appointment. First he is introduced to the VR glasses and the picture was set. Mr. B. put on the glasses, with the straps, the glasses are 
adapted to his head. Mr. B. looks around slowly; he does not move his head at first. "Ah, down there, a lake, yes. Nice area, I want to go there", he says and points to the front. He slowly moves his head and talks to me, "I would like to live there." If he lacks the words to describe the environment, he points with his right hand there, what he virtually sees. He turns his head slightly. When asked if he would like me to turn the wheelchair for him so he can look around, he hesitates and laughs, "No." It seems he needs time to adjust to the view. When he is not able to turn his head any further to see the rest of the virtual environment, I suggest him to turn his upper body to change the view inside the headset.

He leans forward a bit and looks in the depths of the cliff. "Nice", he says and moves the wheelchair slightly with his feet. He looks at the lake, shrugs his shoulders, and says "No sailboat." We're talking about his earlier hobbies, Mr. B. had been a sailor and motorboat driver and tells of his sailing travels in Croatia.

After three minutes, he requests to see something different. Another landscape is being set, after inquiring whether Mr. B. has a fear of heights. "No," he says, "I was a mountaineer!" When asked what he sees now, Mr. B. answers "Houses, church". This time, Mr. B. is more active, he turns his head to the right, as a whole, his body is slightly rotated in a wheelchair. He looks down a bit. "No plane," he says. He turns his head back and forth. The picture may have changed, although Mr. B. had not touched the touchpad of the glasses.

The picture was changed one more time, this time it's the mountain landscape. Mr. B. is more active, he looks to the right and cranes his head, "Is this Dachstein mountain?". He tells that he had climbed Dachstein and it took him three hours. He talks about the cold, windy landscape that is at the top of the summit. It seems like his language is getting a little clearer and more complete. "Oh (...) yes, Dachstein (..)", raves Mr. B. "The summit (..) I was up there", Mr. B. smiles. He looks around calmly, turns his head and says "pines (..)". For longer time of the conversation he has his hands folded. He imagines how he can see all the way to Lake Neusiedl and the Grossglockner mountain. "I can hear deer roar", says Mr. B. and smiles. We talk about hunting; Mr. B. used to be a hunter. He explains that up there, where he is right now, there are no deer "But further down in the forest they are", he says pointing to the floor. He sighs and says, "I want to be there (..)". His left hand has now released his right hand and lies on his upper thigh.

Mr. B. also kept the glasses during the interview, the participant observation was therefore ended.

\subsubsection{Interview}

Everyday life - earlier

Mr. B. comes from south Austria and worked as an electrician. In addition, he trained bodybuilding and spent his holidays with sailing or motor boating in the Mediterranean Sea. Hiking, hunting and skiing were also among his favorite activities.

Everyday life - today

Mr. B. has been living in the care facility for almost 15 years. After a stroke, he has been training hard to regain his skills. He likes go on excursions to Schönbrunn Castle, the Vienna Woods or Laxenburg Castle.

\section{Technology}

Mr. B. is a fan of technology, in his job as an electrician he liked to work with technology. Today his room is equipped with a lot of technology, CD player, computer, printer, TV and cellphone. Mr. B. also uses emails regularly.

Mr. B. sees no disadvantages or risks with the Virtual Reality glasses.

VR experience

Feelings, motives and emotions

Mr. B. does not take off the glasses during the interview, he stays in the mountain scenery and answers the questions. Laughing a little bit, he tells that the glasses with the beautiful mountain view 
awoke homesickness in him, the environment with meadow, mountains and lake reminds him of Styria, where he grew up. It reminds him of his time as hunter.

Presence experience

In order to increase the experience of immersion, Mr. B. would like to see videos, so that he could also observe deer passing by and forest sounds.

Use cases

Mr. B. would like to use the VR glasses again. He would like to use it in his spare time but he would not like to use it for therapies. When he put on the glasses, he looked around and named everything he saw. The glasses could be particularly helpful for the speech therapy, as the virtual content animated him to speak.

Places and destinations already visited

Mr. B. travelled a lot with his wife. They went to Croatia, Turkey and many other places.

I: Where were you everywhere?

B: (laughs) [shows in circles]

I: Everywhere?

B: At the beginning of Turkey, motorboat ride 15 times, sailboat.

I: So you are quite a sporty one?

B: Yes! (laughs)

Seen with the VR glasses

With the VR glasses Mr. B. visited the environment that was selected for the interview. In addition, according to his interest in hiking, another three-dimensional image of mountain peaks was selected too. "Mountains, lake, a house, forest. (.) Not deer. (laughing) ".

Destinations for the VR glasses

Mr. B. talks about various destinations that he would like to visit with the VR glasses. The opera in Graz, Austria and under water environments, but also:

"B: (..) Venice. Rio.

I: Mhm (affirmative). At the carnival?

B: Yes! (laughing) Pretty women! ".

\section{Discussion}

In order to answer the research questions formulated at the outset, the transcripts of the interviews were analyzed.

Research question 1: How do the first encounters of elderly people with Virtual Reality work?

In general, it can be said that the VR glasses were of great interest to the residents. Also the interest in the technology itself was much bigger than expected, no negative prejudices were mentioned. Only one lady, who had had bad experiences with the past Happy Med glasses project, reacted reserved. However, she was glad to have tried the glasses, as she told later.

The duration of the usage was also much longer than expected, in some cases the residents used the glasses for 45 minutes. The participants rejected to take off the glasses during the interview. For the residents it was exciting to explore the natural surroundings. There were no symptoms of cyber sick-ness.

Research question 2: Which motives and sensations accompany the first encounter of the elderly with Virtual Reality?

The residents experienced different impressions during the exposure. Exciting, interesting, beautiful, gorgeous, fascinating, normal, nice, okay and nostalgia were some of the reactions.

Based on the research question "Which fields of application of VR glasses exist from the perspective of the residents?", different application options were proposed by the residents depending on their individual needs. The theme of alternation / seeing something new / distraction 
was mentioned 10 times in the interviews, followed by possibilities of use in the context of therapy or motivation with 8 mentions and relaxation was mentioned three times.

The research question "Which virtual scenarios do the participants wish to visit?" was answered quite homogeneously. The residents named above all Austrian travel destinations, nature scenes in the mountains and forests but also trips to the zoo, to the museum, in churches or even places of everyday life like shopping centers or train stations. It was also of interest to use the VR glasses for watching movies or operas. Far-off destinations such as Rio de Janeiro or the Caribbean are more of an exception. People that had travelled the world are more likely to request such destinations. Foreign destinations that are in close proximity to Austria, such as Venice or Milan, are more of an interest to the residents.

Biographically relevant places such as the parents' home or the place of the wedding were not named decidedly. It is assumed that either the unlimited possibilities of technology with which almost any scene can be recorded was not considered by the participants or that the relationship of the residents with the study staff was not so familiar to express such wishes.

Whether the residents would like to continue using the VR glasses depends heavily on the subjective evaluation of their spare time. If residents, have many appointments in their daily routines, such as therapies or social group activities, they see less need to use VR glasses in their free time.

Residents, who describe themselves as more withdrawn from the community and have had few opportunities to travel, might be keen to catch up on missed opportunities to travel and dream.

Furthermore, technology-inspired residents might also be interested in the possibilities of the technology itself and also want to use moving environments, videos or games in everyday life or as part of therapies.

The participants could also imagine opportunities for other residents of the long-term care facility, especially for residents who spend most of the time in the day room of the ward. For this group of residents, the participants recommend using the VR glasses as an option for distraction and change from everyday life.

\section{Conclusions}

The results of this work show that Virtual Reality is of interest to residents of inpatient longterm care facilities. This work provides first indications of the needs and interests of elderly, dependent people in terms of Virtual Reality. However, there is a need to find out more about inpatient long-term care residents on their experience and needs of the technology, as there are many different kinds of resident target groups within the same facility with different needs toward this technology.

In particular, the use of Virtual Reality with people with dementia requires further research, since different stages of dementia may have different requirements towards the usage. For example, Virtual Reality could be used primarily in people with advanced dementia, where impressive biography work could have a positive effect on possible behavioral problems. But in people with incipient dementia, orientation to the current reality is essential, and Virtual Reality could confuse the people.

An adaptation of the operation of the VR glasses is definitely necessary for a longer-term use of Virtual Reality, not only for the residents themselves, but also for the staff of therapy and care, an intuitive control of the technology is necessary to make them quality to be able to work with their patients.

Building on the results of this work, there are some potential applications for Virtual Reality, ranging from Virtual Reality as a motivation for therapies, to virtual trips for residents who cannot make the journey due to illnesses and impairments. Another option for Virtual Reality applications in the long-term care setting might also be the use of VR as a support during the adaption process for new residents.

Funding: This research received no external funding.

Acknowledgments: Thanks to Sophie Psihoda for supervising this study and to Veronika Schauer and Matei Capatu of Akademie für Altersforschung am Haus der Barmherzigkeit for their support! Parts of this work were 
presented at 8th International Conference on Geriatrics Gerontology \& Palliative Nursing, July 30-31, 2018 । Barcelona, Spain.

Conflicts of Interest: The author declare no conflict of interest.

\section{References}

1. Westenfelder, N. Fitte Senioren - Ist 70 tatsächlich das neue 60? 2017, Retrieved from https://www.srf.ch/news/panorama/fitte-senioren-ist-70-tatsaechlich-das-neue-60, on 2018-05-06.

2. Prütz, F., Seeling, S., Ryl, L., Scheidt-Nave, C. E., Ziese, T., \& Lampert, T. Welche Krankheiten bestimmen die Zukunft? Fehlzeiten-Report 2014; Springer: Berlin, Heidelberg, Germany, 2014; pp. 113-126.

3. Mühl, A. Abschied von zu Hause nehmen - wie betagte Menschen die Zeit ab der Entscheidung bis zum Eintritt in ein Pflegeheim erleben. Unpublished Master Thesis. Universität Wien, Wien, 2011.

4. Luppa, M., Luck, T., Brähler, E., König, H., \& Riedel-Heller, S. Prediction of Institutionalisation in Dementia. Dementia and Geriatric Cognitive Disorders 2008, 26(1), 65-78.

5. Bickel, H. Medizinische und gesellschaftspolitische Herausforderung: Alzheimer Krankheit - Teil 5. 1999, Retrieved from https://www.fes.de/fulltext/asfo/00234004.htm, on 2018-05-06.

6. Welz-Barth, A. Inkontinenz im Alter. Der Urologe 2007, 46(4), 363-367.

7. Altmann, S. Der letzte Umzug: der Weg ins Altersheim für Pflegebedürftige und ihre Angehörigen. 2014, disserta, Germany.

8. Heusinger, J. Alltag im Pflegeheim: Gender adé? In Alter und Geschlecht 2014, Springer, Wiesbaden, Germany, pp. 7-24.

9. Goffman, E. Asylums: Essays on the social situation of mental patients and other inmates. Routledge. 2017

10. Benoit, M., Guerchouche, R., Petit, P.-D., Chapoulie, E., Manera, V., Chaurasia, G., ... Robert, P. Is it possible to use highly realistic virtual reality in the elderly? A feasibility study with image-based rendering. Neuropsychiatric dis-ease and treatment 2015, 11, 557-563.

11. Bowman, D. A., \& McMahan, R. P. Virtual reality: how much immersion is enough? Computer 2007, 40(7).

12. Yu, Z., Zhang, W., Ruan, J., Yao, F., \& Ruan, Q. Virtual Reality in the Assessment and Rehabilitation of the Elderly Population with Physical and Cognitive Impairment, 2017.

13. Monteiro-Junior, R. S., da Silva Figueiredo, L. F., de Tarso Maciel-Pinheiro, P., Abud, E. L. R., Braga, A. E. M. M., Barca, M. L., ... \& Laks, J. Acute effects of exergames on cognitive function of institutionalized older persons: a single-blinded, randomized and controlled pilot study. Aging clinical and experimental research 2017, 29(3), 387-394.

14. Cook, D., \& Coldham, G. VR Useability from Elderly Cohorts: Preparatory challenges in overcoming technology rejection. NITC Sri Lanka Conference 2017, Colombo.

15. Mühlegger, V. VR ['vi:-'ar] Senior: Aspekte, die für die erfolgreiche Nutzung von Virtual-Reality-Brillen im Alter besonders zu beachten sind. Unpublished Bachelor Thesis, 2018. Ferdinand-PorscheFernfachhochschule, Wiener Neustadt.

16. Mosadeghi, S., Reid, M. W., Martinez, B., Rosen, B. T., \& Spiegel, B. M. R. Feasibility of an Immersive Virtual Reality Intervention for Hospitalized Patients: An Observational Cohort Study. JMIR Mental Health 2016, 3(2).

17. Agronin, M. (2016, März 21). How Virtual Reality Can Enhance the Life of Older Adults. Wall Street Journal. Retrieved from http://blogs.wsj.com/ex-perts/2016/03/21/how-virtual-reality-can-enhance-the-life-ofolder-adults/ on 2018-05-06.

18. Rendever. Virtual Reality for Seniors. Retrieved from http://rendever.com/ on 2018-05-06.

19. LaViola Jr, J. J. A discussion of cybersickness in virtual environments. ACM SIGCHI Bulletin 2000, 32(1), 4756.

20. Hauge, S., \& Kristin, H. The nursing home as a home: a field study of residents' daily life in the common living rooms. Journal of Clinical Nursing 2008, 17(4), 460-467.

21. Chau, B. Rendever helps debilitated patients experience outside world with friends \& family. Retrieved from https://www.imedicalapps.com/2017/03/virtual-reality-rendever/ on 2018-05-06.

22. Witzel, A. Das problemzentrierte Interview. In G. Jüttemann (Hrsg.), Qualitative Forschung in der Psychologie: Grundfragen, Verfahrensweisen, Anwendungsfehler. Weinheim: Beltz, Germany, 1985; pp. 227-255)

23. Lamnek, S. Qualitative Sozialforschung. Lehrbuch (5. überarbeitete Auflage). Weinheim: Beltz, 2005.

24. Samsung. Samsung Gear VR 2017 । Samsung Electronics Österreich. Retrieved from http://www.samsung.com/at/wearables/gear-vr-r324/ on 2018-06-05 